\title{
Estimating Saudi Arabia's Regional GDP Using Satellite Nighttime Light Images
}

Hector G. Lopez-Ruiz, Jorge Blazquez and Fakhri Hasanov 


\section{About KAPSARC}

The King Abdullah Petroleum Studies and Research Center (KAPSARC) is a non-profit global institution dedicated to independent research into energy economics, policy, technology and the environment across all types of energy. KAPSARC's mandate is to advance the understanding of energy challenges and opportunities facing the world today and tomorrow, through unbiased, independent, and high-caliber research for the benefit of society. KAPSARC is located in Riyadh, Saudi Arabia.

This publication is also available in Arabic.

\section{Legal Notice}

(C) Copyright 2019 King Abdullah Petroleum Studies and Research Center ("KAPSARC"). This Document (and any information, data or materials contained therein) (the "Document") shall not be used without the proper attribution to KAPSARC. The Document shall not be reproduced, in whole or in part, without the written permission of KAPSARC. KAPSARC makes no warranty, representation or undertaking whether expressed or implied, nor does it assume any legal liability, whether direct or indirect, or responsibility for the accuracy, completeness, or usefulness of any information that is contained in the Document. Nothing in the Document constitutes or shall be implied to constitute advice, recommendation or option. The views and opinions expressed in this publication are those of the authors and do not necessarily reflect the official views or position of KAPSARC. 


\section{Key Points}

he increasing availability of data from technologies such as mobile phones, satellites and connected devices means that there are many new possible sources of economic data.

This study analyzes the potential use of nighttime light images from satellites to provide a regional distribution of Saudi Arabia's gross domestic product (GDP). It offers new insights into the following areas:

The distribution of GDP in Saudi Arabia is concentrated in three provinces, areas characterized by the oil industry, tourism and government activities (Eastern Province, Al-Riyadh and Makkah Al-Mukarramah).

The employment elasticities of GDP at the regional level are in line with the values predicted by production function theory (0.7).

The regional impacts of the 2009 and 2015 oil price crashes and the effects of Saudi Arabia's responses in both cases.

The opportunity to establish a new way of estimating regional GDP for Saudi Arabia, and to develop other regional economic indicators on a monthly or quarterly basis.

Figure 1. Satellite VIIRS-DNB data for March 2015.

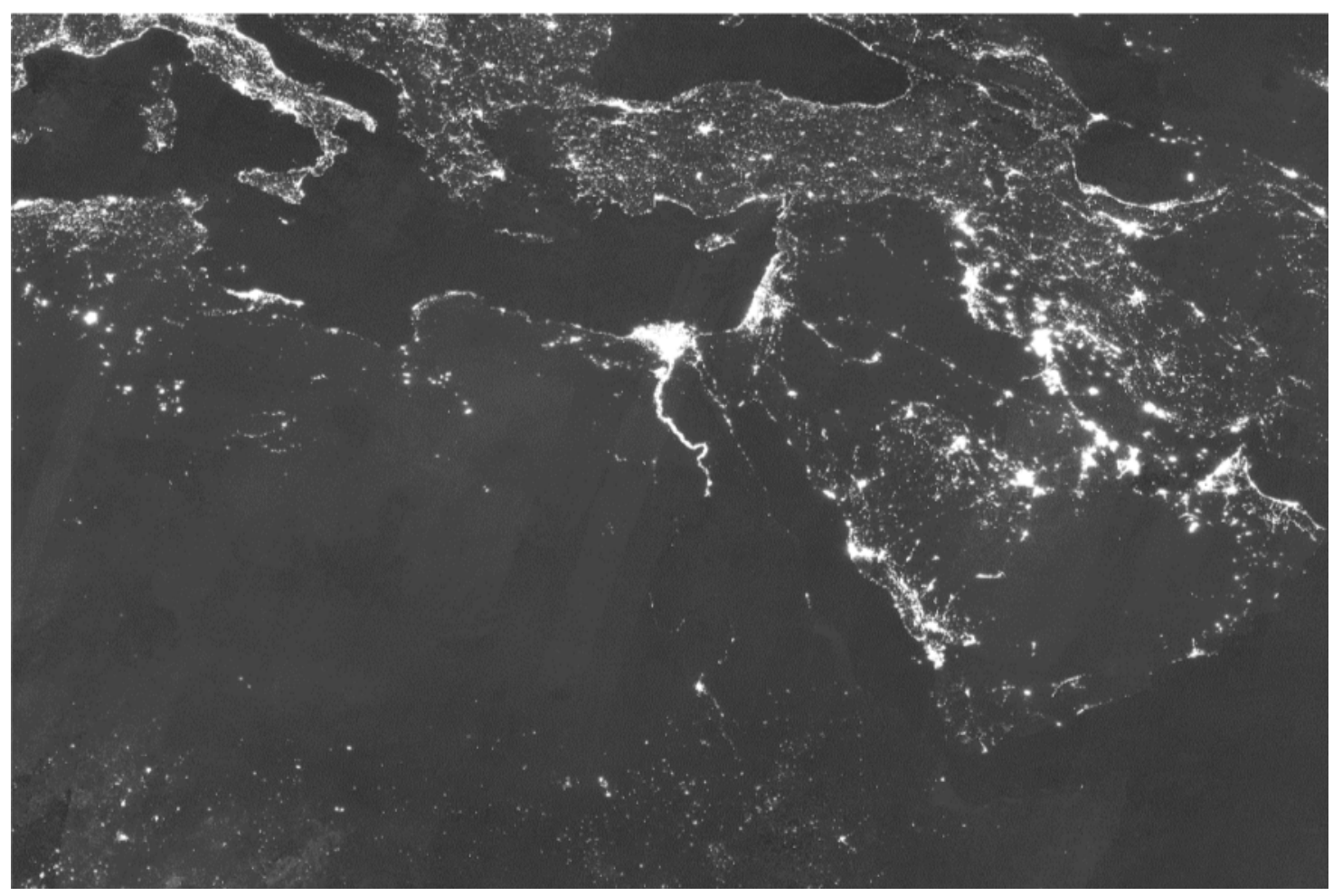

Source: NOAA. 


\section{Summary}

N

ew technologies such as satellite images and smartphones are not only changing economic activity; they are also providing new sources of economic data. These new data can be used to enhance our understanding of socio-economic activities and official statistics or to fill gaps where official information is unavailable. To the best of our knowledge, this is the first study that assesses the gross domestic product (GDP) of Saudi Arabia's 13 provinces using nighttime light (NTL) satellite images. These images are provided free of charge by the National Oceanic and Atmospheric Administration (NOAA). The analysis, conducted using the production function framework, shows that the GDPs of Saudi Arabia's 13 regions are consistent with their economic fundamentals. This shows the use value of satellite NTL images for empirical analyses. Moreover, this study finds that three regions generate around $60 \%$ of the country's total GDP. However, the estimated level of GDP per capita among these regions varies substantially due to their different economic structures. The analysis also shows that the Eastern Province, with its strong oil and gas industry, is more exposed to international oil price shocks than the other provinces of Saudi Arabia.

Keywords: GDP, nighttime light satellite image, regional activity 


\section{Introduction}

he emergence of new technologies is not only changing economic activity, but also the way economists measure economic activity. Nighttime light (NTL) satellite images and smartphone data are two new sources of information that can help measure and track socio-economic activity (Mukin and Garret 2018). These new means of measuring economic and human activity are especially relevant in economies located between the tropics (Hu et al. 2019), such as Saudi Arabia. They can be used in addition to traditional statistical tools, but the benefit of these new measurements is that they allow analysts to capture and calculate economic growth factors in extremely short timeframes.

Using satellite images to estimate regional economic activity is not new. Since the foundational paper by Elvidge et al. (1997), a growing number of studies have used NTL images as a proxy for economic and human activity. Elvidge et al. (2012) use NTL and population density to measure income distribution at the national and regional levels. Pinkovskiy and Sala-I-Martin (2016) focus on income distribution and inequality and evaluate the quality of national surveys of developing countries based on NTL satellite images. Doll et al. (2006) explore the relationship between NTL and regional economic activity for 11 European countries, presenting the information in a grid rather than in administrative units. Chen and Nordhau (2011) find that NTL images can be a valid indicator of economic activity or gross domestic product (GDP), especially in countries with low-quality statistical systems.

Using NTL to explore the regional structure of Saudi Arabia's economy produces interesting results. Saudi Arabia is the largest oil exporting country and the second largest oil producer (EIA 2019). Most of the country's oil production is concentrated in two regions: the Eastern Province and, to a lesser extent, the Central Province. Makkah and Medinah, two Islamic holy cities with many domestic and international visitors, are in the west of the country. The different economic structures of these regions might lead to differing levels of economic activity and, potentially, to differing GDP or income per capita. Saudi Arabia's General Authority for Statistics (GaStat), along with other related agencies, conducts regional labor market and household surveys. It reports regional employment and regional electricity consumption by broad consumer types, such as industry, agriculture and commercial services. However, to the best of our knowledge, no agency publishes regional GDP. This informational gap makes it difficult to assess regional economic development in Saudi Arabia. It is important to investigate regional economic development from many perspectives through key indicators such as GDP, investment, employment, wages and consumption.

This kind of investigation should provide decision-makers with a better understanding of each region's development issues so that they can implement region-specific actions to improve social-economic development and reduce poverty. This analysis is of particular use for Saudi Arabia, where economic activity is heavily dependent on oil and where there is an urgent need for economic diversification, as set out in the Saudi Vision 2030 strategy. Taking the relevant measures to achieve a proportional and balanced economic development in the regions would help diversify the country's economy. Estimations of regional GDP would also help policymakers design plans for each region's development.

The objective of this study is to construct regional GDP estimations for Saudi Arabia using NTL images. In this study we will: 
estimate regional GDP for Saudi Arabia from 1992-2017 using NTL images;

estimate the impact of regional employment on the calculated regional GDP in the production function framework across 13 regions from 2001-2017;

examine the impact of the oil price collapses in 2008-2009 and 2014-2015 on regional GDP.

The objective of the aforementioned economic analysis is to ensure that the estimated regional GDP data, using NTL observations, are consistent with their theoretically predicted determinants and reflect changes in Saudi Arabia's economy.

Through this analysis, we estimate the Saudi Arabian labor elasticity of output to be around 0.7 and to be statistically significant for most regions. This is particularly important since production function theory states that employment is one of the drivers of production, and the labor elasticity of output is usually found to be around 0.67 (Cobb and Douglas 1928; Douglas 1976; Solow 1988).

This study also shows, unsurprisingly, that the Saudi business cycle is strongly influenced by the international price of oil (Mehraraa and Oskouib 2007). Around $43 \%$ of the country's economic activity centers on crude petroleum, natural gas production and petroleum refining (SAMA 2017). We find that the negative oil price shocks in 2008-2009 and 2014-2015 had a stronger impact in the Eastern Province than in Makkah Province. This finding is consistent with the economic structure of these regions.
The main contribution of this study is that it is the first to regionalize Saudi GDP using NTL images. It will enable future analyses of the regional characteristics of Saudi Arabia's economy. It could also enable the development of a regional economic indicator that could be estimated on a monthly or quarterly basis, given that the NTL images are produced daily.

The paper is organized as follows: section 2 describes the study's analytical strategy, together with a description of the data used and the research methodology. Section 3 presents an empirical analysis and discusses the study's findings. Section 4 concludes the study. 


\section{Analytical Strategy, Methodology and Data}

$\mathbf{T}$

his paper combines regional NTL intensity analysis and standard econometric analysis. It contributes to the growing literature on the relationship between economic activity and NTL radiance captured by satellites. Previous studies that have explored this relationship include Lopez-Ruiz et al. (2019), Jing et al. (2015), Henderson et al. (2010), Elvidge et al. (2012), Pinkovsky et al. (2016), Doll et al. (2006), Townswend et al. (2010), Chen et al. (2011) and Shi et al. (2014). These studies all find that the use of electricity at night by industry and households is a direct reflection of economic activity. 


\section{Strategy for the Empirical Analysis}

The analysis in this study will be conducted in three stages. First, we regress GDP $\left(G D P_{t}\right)$ on nationwide NTL intensity $\left(N T L_{t}\right)$ to see how well the latter can explain the former:

$$
G D P_{t}=\alpha_{0}+\alpha_{1} N T L_{t}+\varepsilon_{t}
$$

Here and hereafter, small letters indicate the natural logarithm expression of the variables. For example, $g d p$ is the natural log of GDP; $\varepsilon$ is the error term and $t$ indicates time.

We are well aware that GDP as a measure of economic activity or output of an economy includes economic fundamentals such as capital and labor (Cobb and Douglas 1928; Solow 1988). However, we only use NTL intensity in equation (1) as an explanatory variable because our aim in the regression analysis is to establish the explanatory power of NTL intensity for GDP. If we include capital and/or labor in the regression equation, then the variance of GDP will be explained by the variance of all the regressors, not purely that of NTL intensity. The aim of this stage is to determine whether the regional NTL intensity can be used to calculate regional GDP.

Second, we calculate the GDP of 13 regions using regional NTL intensities as shares of national NTL intensities:

$$
G D P_{t, i}=\frac{N L T_{t}}{N L T_{t, i}} G D P_{t}
$$

Where $i$ indicates region.

Third, we use the production function framework to regress the calculated regional GDP on its economic fundamentals such as regional employment (ET), depending on the availability of regional data, to see how consistent the calculated regional GDP is with its economic fundamentals. (It would be advisable to have capital stock in equation (3) also.
However, there is no available regional capital stock time series data to the best of our knowledge). This stage aims to validate the calculated regional GDP data to show whether or not it can be considered economically meaningful.

$$
g d p_{t, i}=\alpha_{0}+\alpha_{1} e t_{t, i}+\varepsilon_{t, i}
$$

Here, $g d p_{(t, i)}$ and $e t_{(t, i)}$ are the natural logarithmic expressions of GDP and employment; $\alpha_{1}$ is GDP elasticity with respect to employment; $\varepsilon_{(t, i)}$ is the error term, and $t$ and $i$ are time and regions, respectively. Production function theory states that the employment elasticity of the output should be positive and usually around 0.67 . 


\section{Data}

NTL. The satellite imagery divides Saudi Arabia into 13 provinces: Aseer, Al-Baha, the Northern Borders, Al-Jouf, Al-Medinah Al-Monawarah, Al-Qassim, Al-Riyadh, the Eastern Province, Hail, Jazan, Makkah Al-Mukarramah, Najran and Tabouk. We collected NTL image data for 1992-2017 from the National Oceanic and Atmospheric Administration (NOAA).

The nationwide NTL intensity $\left(N T L_{t}\right)$ is the sum of regional NTL intensity $\left(N T L_{t, i}\right)$ :

$$
N T L_{t}=\sum_{\mathrm{i}=1}^{13} \mathrm{NTL}_{t, i}
$$

The NTL satellite pictures from 1992-2013 come from the Operational Linescan System (OLS) in the Defense Meteorological Satellite Program (DMSP). The images for 2014-2017 come from the Visible Infrared Imaging Radiometer Suite Day and Night Band (VIIRS-DNB). Figure 1 is an example of a VIIRS-DNB image.

Both satellite and infrared images are available for 2013. From 2013, the NTL data have monthly and daily frequencies. Annual composites are available for VIIRS-DNB for certain years, while OLS-DMSP NTL pictures are available as annual composites from 1992 to 2013. In order to work with both satellite and infrared images, we created annual composites for VIIRS-DNB using the monthly data available from NOAA.

The difference for the values in the NTL radiance series is because they come from two different source technologies: DMSP-OLS and VIIRS-DNB. Although they both capture the values of radiance on the surface of the earth in watts per square centimeter (cm2) per steradian, the sensitivity of their sensors is different. As Figure 2 shows, there is a big jump between the values for radiance in 2014 . The difference between these two series is twofold:

The visible sensitivity of the satellite equipment used to capture the radiance values. Please refer to Jing (2015) for a discussion on the differences in the sensitivities of both technologies.

The values for radiance reported by NOAA in a yearly format are missing for some years. As such, we built a yearly composite equal to the sum of the monthly values.

In the methodology section, we discuss how we integrated this change from DMSP-OLS to VIIRS-DNB into the statistical analysis by using a dummy variable. This approach allowed us to keep using raw values to which we did not apply any type of adaptive factor.

GDP. GDP is calculated using 2010 prices and expressed in million Saudi riyals (SAR). The data was provided by GaStat (2019a) from 1992-2017, to be consistent with the availability of NTL data. According to the National Accounts of Saudi Arabia, GDP is the sum of values added by domestic producers to product prices, plus customs tariffs (GaStat 2019b). It is alternatively defined as the sum of all outputs, less the sum of intermediate consumption plus net taxes on products (taxes - subsidies) not included in the values of outputs. GaStat uses 2010 as its base year in calculating real values, i.e., values at constant prices.

ET is the term used to express employment in each of the 13 regions. The data are collected from GaStat's regional Labor Force Surveys (GaStat 2019a). According to GaStat's Labor Market Bulletin Methodology, the employment data includes all male and female citizens over 15 years of age. The data are only available from 2000; hence we collected them for 2000-2017. Figure 2 illustrates the log levels of GDP and NTL from 1992-2017. 
Figure 1. Satellite VIIRS-DNB data for March 2015.

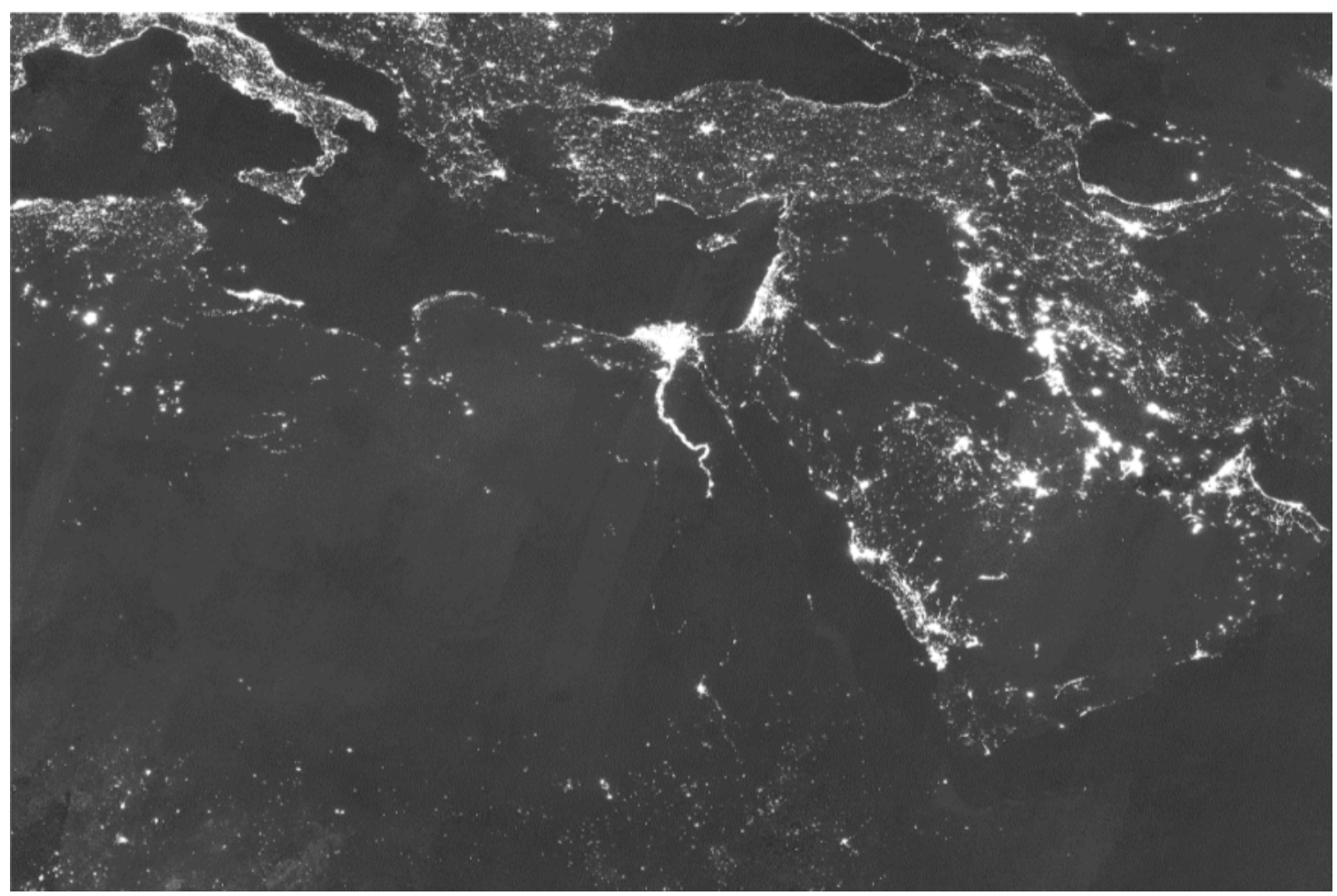

Source: NOAA.

Figure 2. Log levels of the variables.

nlt

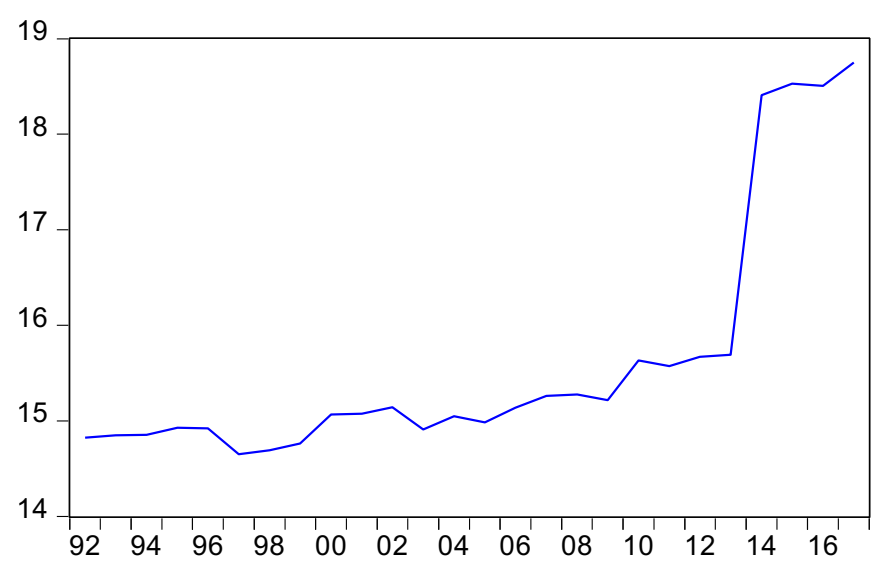

gdp

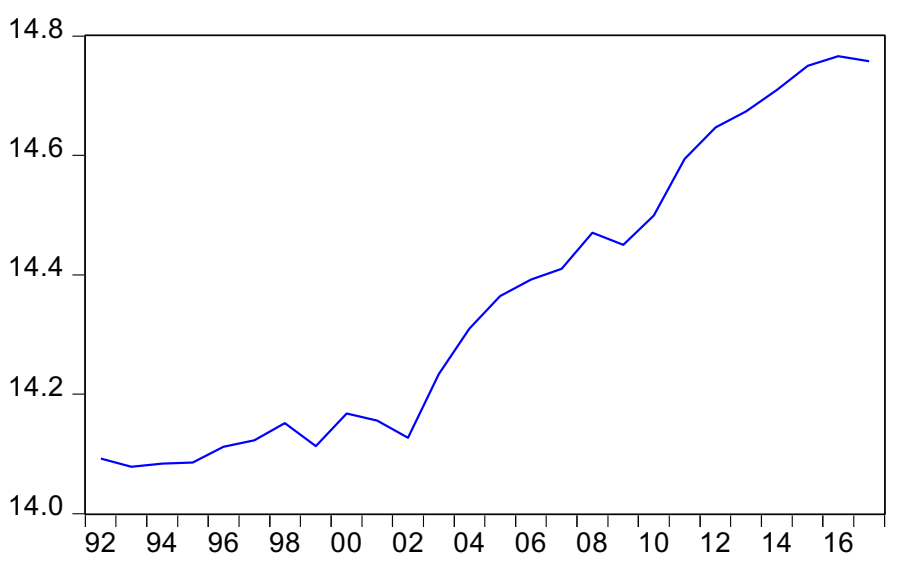

Sources: NOAA (2019) and GaStat (2019a).

Note: The regional and total employment data are given in Appendix A. 


\section{Methodology}

This paper employs two methods. The first is used to process the satellite radiometry files distributed by NOAA in order to calculate the sum of radiance for each province in Saudi Arabia. We used the same process as described by Lopez-Ruiz (2019). We used the code provided by Alhassan (2019) to expedite the calculation of radiance for all provinces between 1992 and 2017.

The second method is econometric. We use ordinary least squares (OLS) in the first stage to estimate equation (1). In the third stage, we conduct a cointegration analysis. We first establish the stochastic properties, i.e., integration orders, of the variables of interest. For this, we perform the augmented Dickey Fuller (ADF) unit root test (Dickey and Fuller 1981). We also perform unit root tests with structural breaks, such as those developed by Perron and Vogelsang (1992a, 1992b), and Vogelsang and Perron (1998), in case the ADF test results do not appear reasonable and/or are inconsistent with the graphical illustration of a given variable. Once the integration orders of the variables are identified, we use fully modified least squares (FMOLS) to estimate the level relationship between the variables in equation (3). We perform an Engle-Granger (EG) cointegration test (Engle and Granger 1987) to see whether the variables establish a long-run relationship and are consistent with economic theory. FMOLS was developed by Phillips and Hansen (1990) and has a number of advantages of over OLS that we do not discuss here. The main advantage of FMOLS in this research is that it produces an asymptotically unbiased estimator and allows for conventional testing and inferencing, such as the t-test and f-test.

One could argue that using the approach developed by Johansen (1988) and Johansen and Juselius (1990, 1992), or the autoregressive distributed lags bounds testing (ADLBT) approach developed by
Pesaran and Shin (1999) and Pesaran et al. (2001), would be preferable over the EG cointegration test. The Johansen method can reveal more than one cointegrating relationship if the variables number more than two, and if such relationships exist. It can also address weak exogeneity issues, which is important in the short run analysis, i.e., in error correction modeling. The Johansen method and ADLBT can address simultaneity issues in a more effective way than the EG test.

There are three reasons why we use the EG approach rather than the other methods. The first is that a cointegration approach can show whether constructed regional GDP is consistent with economic fundamentals, such as employment. We assess whether regressing the regional GDP calculated using NTL on real-time regional employment data surveyed by GaStat produces coefficients with a theoretically expected sign and size and of statistical significance (e.g., the employment elasticity of GDP should be positive at around 0.67 but less than unity in the majority of the regional estimations). We do not aim to use the results of the cointegration analysis for policy analysis or forecasting. The second reason for using the EG cointegration test is that we do not benefit from the above-mentioned advantages of the Johansen and/or ADLBT methods as (a) we have only two variables (GDP and ET) in the cointegration analysis and thereby the number of cointegrating relationships cannot be more than one; (b) we do not conduct short-run analyses. Lastly, our sample size is quite small: we only have 18 annual observations, and the Johansen and ADLBT methods require a sufficiently large sample. However, FMOLS uses non-parametric transformation to remove serial correlation and address other issues such as endogeneity. It therefore does not consume data for lag lengths (see Phillips and Hansen [1990] for further discussion). 


\section{Empirical Analysis and Discussion}

$\mathrm{T}$ his section details the empirical analysis, following the methodology outlined in the previous section. It also discusses the findings of the study.

\section{Relationship between GDP and nationwide NTL}

In this stage, we only regress GDP on NTL. It is clear from Figure 2 that NTL had a significant level shift in 2014; the regression analysis should take this into consideration to obtain accurate results. We achieve this by including a dummy variable, DSH2014, which takes unity for 2014-2017 and zero otherwise in the regression equation. The estimation results are tabulated in Panel A of Table 1.

Figure 2 also shows that GDP drops significantly in 2002, which should also be accounted for in the estimations. We capture this drop by introducing a pulse dummy variable, DP2002, which takes unity in 2002 and zero otherwise. We also include a time trend (TREND) in the regression equation, since $G D P$ trends over time. Panel B of Table 1 presents the estimation results.

In Panel B, the estimation takes into consideration the extraordinary changes in both national NTL and $G D P$. It reports that $97 \%$ of the variation in $G D P$ can be explained by NTL, alongside TREND and DP2002. This is a high level of approximation. Even if we do not take into consideration the extraordinary changes in $G D P, N T L$ in itself still explains $89 \%$ of the variation in $G D P$.

The estimation results indicate that NTL intensity could be used to calculate regional GDP.

Table 1: Relationship between GDP and nationwide NTL.

\begin{tabular}{l|l|l} 
& \multicolumn{1}{|c|}{ Panel A } & \multicolumn{1}{c}{ Panel B } \\
\hline Regressor & Coefficient (P-value) & Coefficient (P-value) \\
\hline$c$ & $5.781(0.000)$ & $11.265(0.000)$ \\
\hline$N T L_{t}$ & $0.563(0.000)$ & $0.1845(0.003)$ \\
\hline$N T L_{t}{ }^{*} \mathrm{DSH} 2014_{t}$ & $-0.080(0.000)$ & $-0.025(0.010)$ \\
\hline DP2002 & - & $-0.166(0.001)$ \\
\hline$T R E N D$ & - & $0.0214(0.000)$ \\
\hline $\mathrm{R}^{2}$ & 0.887 & \\
\hline Adjusted R ${ }^{2}$ & 0.878 & 0.974 \\
\hline
\end{tabular}

Notes: Dependent variable is GDP $;$ P-value = probability values of a given coefficient; Estimation period: $1992-2017$.

Source: KAPSARC calculations. 


\section{Calculating Regional GDP Using NTL}

0

nce NTL has been established as a valid tool to measure national GDP, it is possible to use it to determine regional GDP. We achieved this by taking the share of each region's NTL intensity over the national NTL intensity and multiplying it by the national GDP to calculate each region's GDP. Figure 2 illustrates the calculated regional GDP series and national GDP.

Figure 3 shows that the trend in the calculated regional GDP series follows that of the national GDP.
This suggests that the calculated regional GDP reflects the country's overall economic development. For example, the drop in national GDP in 2002, captured by the econometric estimations above, is replicated in regional GDP (see the vertical lines in the regional GDP series indicating the drop). The slowdown in the Saudi economy since 2014, due to the significant decline in international oil prices, is also reflected in the GDP of many regions, including Aseer, Al-Baha, Jazan, Hail and Al-Jouf.

Figure 3. Regional and national GDP.

GDP_ASR

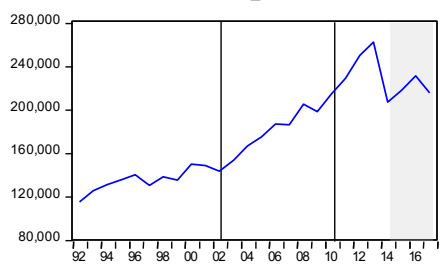

GDP_MED

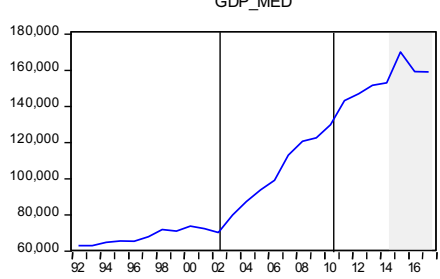

GDP_HAL

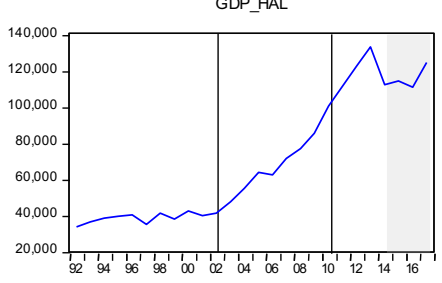

GDP_TBK

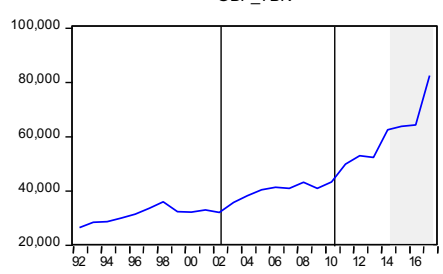

GDP_BAH

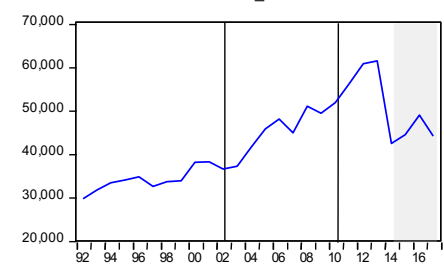

GDP_QAS

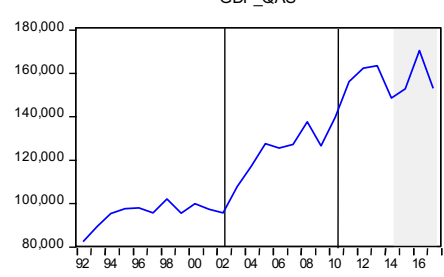

GDP_JZN

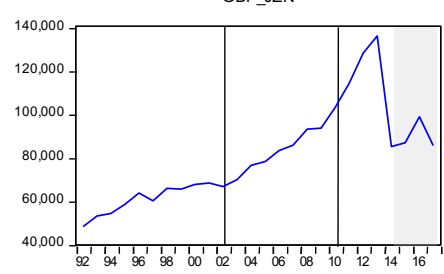

GDP, real, LCU, Riyal Millions, 2010 prices

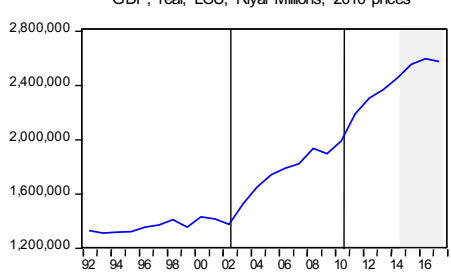

GDP_NBR

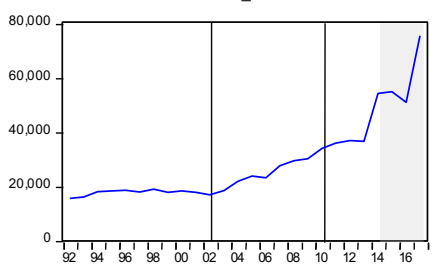

GDP_RYD

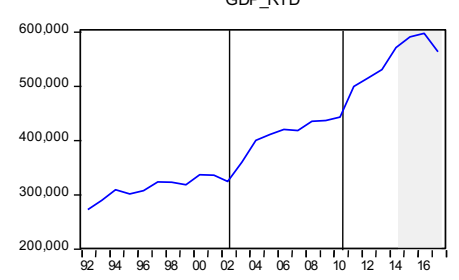

GDP_MAK

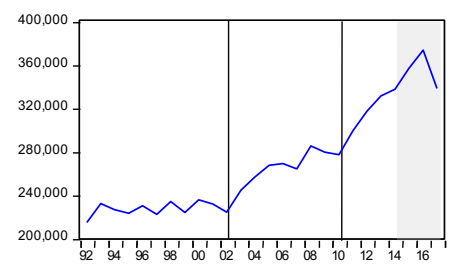

GDP_JOF

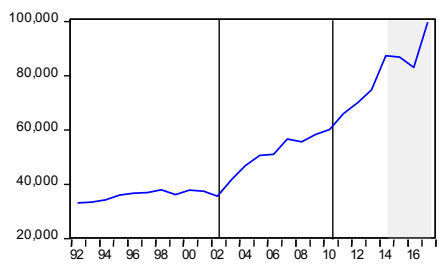

GDP_ERG

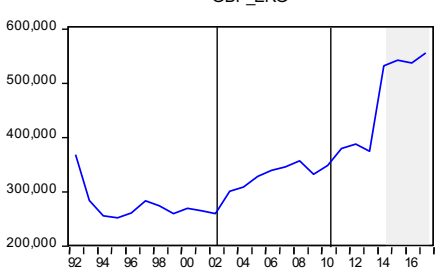

GDP_NJR

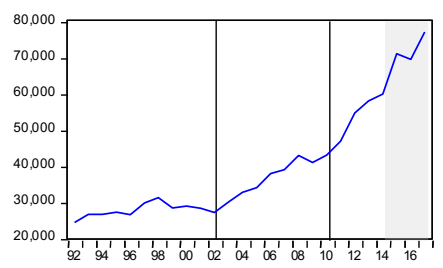

Note: $\mathrm{ASR}=$ Aseer; BAH = Al-Baha; NBR = Northern Borders; JOF = Al-Jouf; MED = Al-Medinah Al-Monawarah; QAS = Al-Qassim; RYD = Al-Riyadh; EPR = Eastern Province; HAL = Hail; JZN = Jazan; MAK = Makkah Al-Mukarramah; NJR = Najran; TBK = Tabouk.

Source: KAPSARC calculations. 


\section{Cointegration Analysis Between Regional GDP and Regional Employment}

A s mentioned in the previous section, we conducted a cointegration analysis between regional GDP and regional employment to assess the relationship between the calculated regional GDP and regional employment figures. Following the methodology above, we first identified the integration order of GDP and ET. We conclude that the variables across the 13 regions are integrated of order one based on the ADF test results. The test results are not reported here but are available from the authors upon request.
Once we conclude that the variables are of the first order integrated, we conduct the cointegration analysis. The analysis covers two stages. The first is estimating equation (3) to find out the long-run/ level relationships between GDP and employment in the 13 regions. The second is performing the EG cointegration test to establish whether long-run relationships exist between the regional variables.

Table 2 shows that either $t$ or $z$, or both in most cases, indicates an existence of cointegration,

Table 2. Relationship between regional GDP and regional employment.

\begin{tabular}{l|l|l|l|l|l|l}
\multirow{2}{*}{$\begin{array}{l}\text { Region/ } \\
\text { regressor }\end{array}$} & \multicolumn{4}{|c|}{ Long-run estimation } & \multicolumn{2}{l}{ Cointegration test } \\
\cline { 2 - 6 } & $e t_{t, i}$ & $c$ & TREND & DUMMY & $t$ & $z$ \\
\hline ASR & $0.508(0.000)$ & $4.464(0.001)$ & $0.018(0.000)$ & $-0.210(0.005)$ & $-4.426(0.046)$ & $-18.199(0.049)$ \\
\hline BAH & $0.619(0.000)$ & $3.590(0.024)$ & - & $-0.318(0.020)$ & $-3.399(0.086)$ & $-13.722(0.077)$ \\
\hline NBR & $0.337(0.360)$ & $2.853(0.324)$ & $0.062(0.013)$ & - & $-4.273(0.069)$ & $-51.870(1.000)$ \\
\hline JOF & $0.004(0.952)$ & $7.624(0.000)$ & $0.056(0.000)$ & $-0.136(0.018)$ & $-4.053(0.082)$ & $-17.683(0.060)$ \\
\hline MED & $0.483(0.001)$ & $2.900(0.053)$ & $0.042(0.000)$ & - & $-2.542(0.556)$ & $-13.356(0.230)$ \\
\hline QAS & $0.674(0.000)$ & $3.129(0.000)$ & - & - & $-3.403(0.085)$ & $-14.588(0.056)$ \\
\hline RYD & $0.644(0.000)$ & $3.546(0.001)$ & - & - & $-3.315(0.101)$ & $-42.337(0.000)$ \\
\hline EPR & $0.742(0.000)$ & $2.299(0.103)$ & - & $0.243(0.050)$ & $-3.839(0.048)$ & $11.831(1.000)$ \\
\hline HAL & $0.369(0.007)$ & $2.099(0.070)$ & $0.082(0.000)$ & $-0.307(0.000)$ & $-6.339(0.003)$ & $370.302(1.000)$ \\
\hline JZN & $0.092(0.087)$ & $6.971(0.000)$ & $0.057(0.000)$ & $-0.488(0.000)$ & $-4.296(0.063)$ & $-18.472(0.027)$ \\
\hline MAK & $0.631(0.000)$ & $3.359(0.000)$ & - & $0.095(0.028)$ & $-2.760(0.226)$ & $-14.656(0.055)$ \\
\hline NJR & $0.754(0.029)$ & $0.442(0.872)$ & $0.023(0.181)$ & $0.137(0.010)$ & $-3.908(0.106)$ & $-14.856(0.144)$ \\
\hline TBK & $0.527(0.016)$ & $4.196(0.095)$ & - & $0.456(0.000)$ & $-3.839(0.043)$ & $-73.210(0.000)$
\end{tabular}

Notes: Dependent variable is $g d p_{t, i}$ numbered from 1 to 13 according to the regions. The values in parentheses are the probabilities of the coefficients; estimation period: 2001-2017. $t$ and $z=$ tau-statistic and z-statistic of the Engle-Granger test, respectively.

Source: KAPSARC calculations. 
i.e., a long-run relationship between the variables. Having long-run relationships between the variables indicates that estimated coefficients in the table are in line with the production function theory. Indeed, the estimated employment elasticities of GDP are (a) positive for all 13 regions, (b) statistically significant for 11 regions, and (c) around 0.67 for eight regions. Overall, the estimation results show a high correlation between regional GDP and regional employment. What is more, the estimated labor elasticities for Saudi Arabian regions are in line with the value of 0.7 usually put forward by the production function theory. 


\section{Saudi Arabian Regional Distribution Analysis}

$\mathrm{B}$ uilding on this analysis, Figure 4 shows the relationship between the estimated regional GDP and the economically active population in each region. The diagonal of the figure represents an equal distribution of the economically active population and estimated GDP. It is not surprising that a significant amount of economic activity $(22 \%)$ is concentrated in the Eastern Province, as it contains $20 \%$ of the country's total economically active population. Al-Riyadh has the same share of economic activity (22\%) as the Eastern Province but contains $37 \%$ of the country's total economically active population. This province contains the capital city and most governmental institutions and organizations. Interestingly, the province of
Makkah, with $22 \%$ of the country's economically active population, has a $13 \%$ share of its GDP. Saudi Arabia's religious tourism (national and international) is concentrated here. (In 2017 around 19.1 million pilgrims carried out Umrah and 2.4 million carried out Hajj. The population of this province is 8.3 million).

Figure 5 shows the 'Lorenz curve' for Saudi Arabia's population against GDP. The Lorenz curve is often used to depict income inequality among households, but it can illustrate different economic concepts (Hainsworth 1964). The curve in Figure 5 provides an idea of the regional distribution of GDP per capita. As expected, the Eastern Province

Figure 4. Economically active population distribution and estimated GDP, 2017.

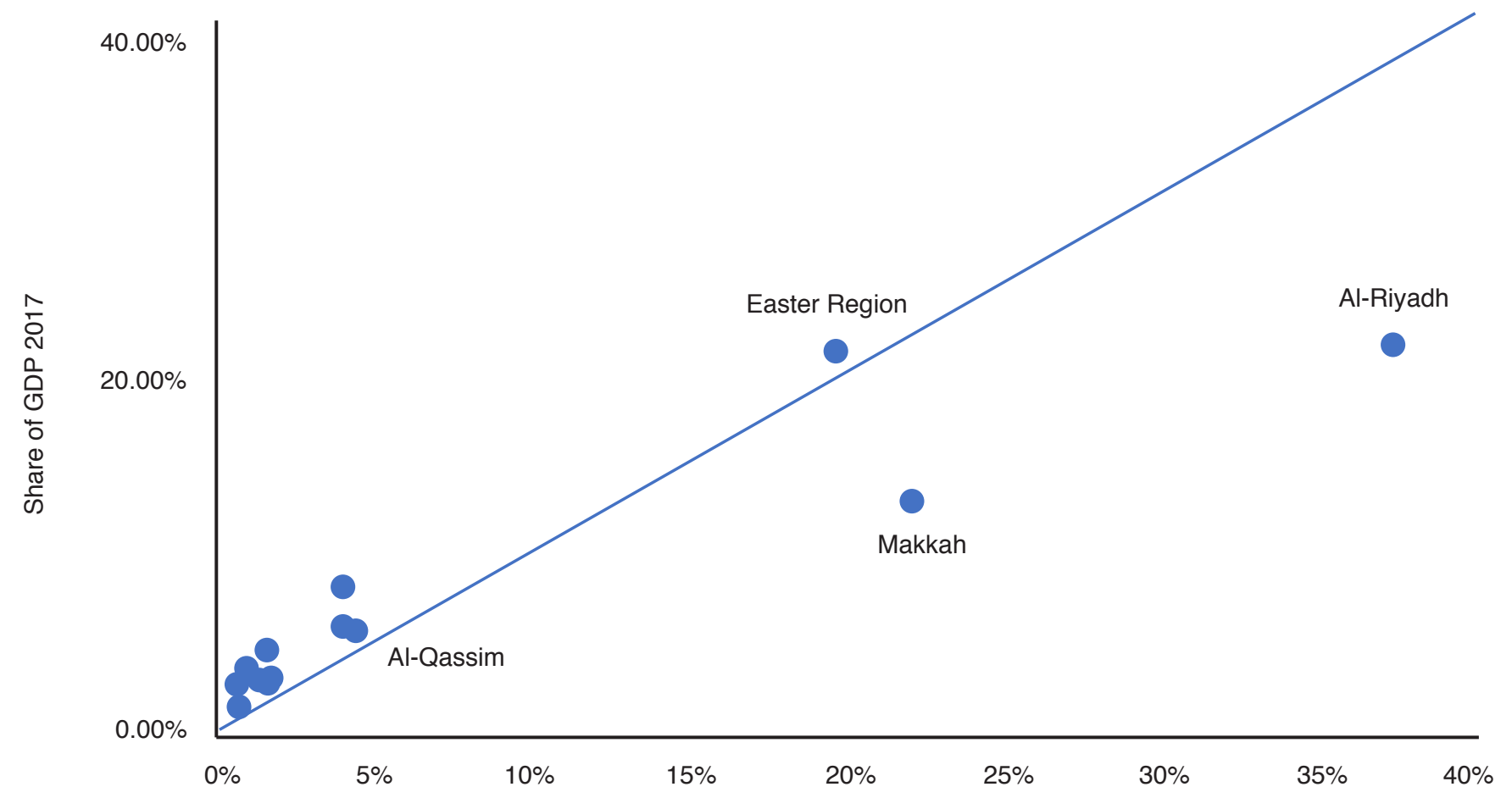

Share of economically active population 2017

Source: KAPSARC calculations. 
Figure 5. Share of population and GDP.

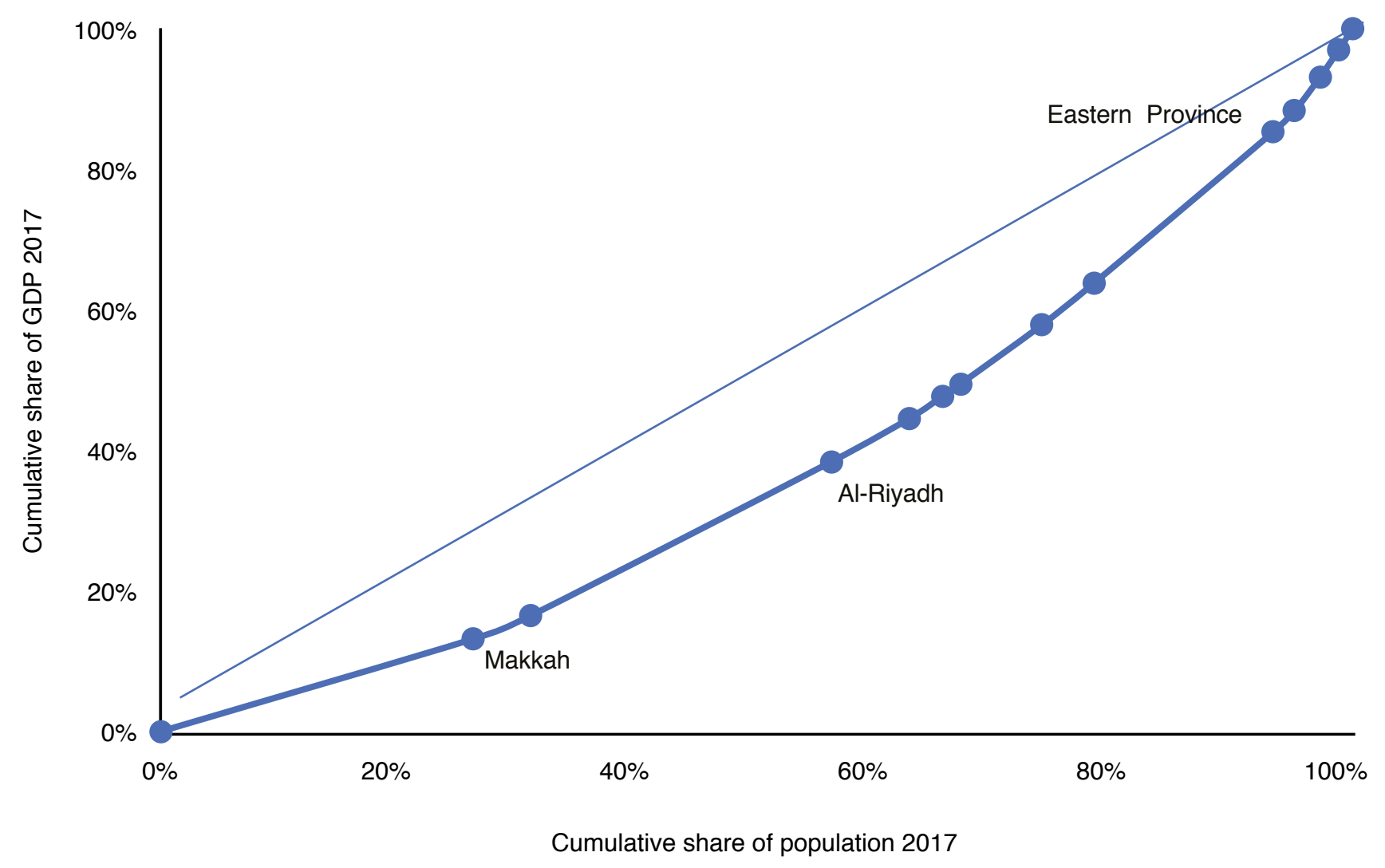

Source: KAPSARC calculations.

has one of the highest levels of GDP per capita, while Makkah has the country's lowest GDP per capita. This is unsurprising since Makkah's main activity is religious tourism, a sector with a higher labor intensity than that of oil extraction, requiring a more capital-intensive structure. Despite most governmental activity being concentrated in Al-Riyadh, it is in the middle of the distribution curve. 


\section{Economic Analysis of the 2008-2009 and 2014-2015 Oil Price Declines in Saudi Arabia}

Whe last part of the analysis compares the regional impact of the sharp oil price declines in 2008-2009 and 2014-2015. In 2008-2009, the international price for Arabian Light declined by $35 \%$ (SAMA 2017). This decline in the oil price led to a recession in Saudi Arabia, with GDP declining by $2.1 \%$ in 2009 and the public deficit reaching $5.4 \%$ of GDP. In 2015 the international price of Arabian Light declined by $49 \%$. In 2010 the oil price recovered by $27 \%$ compared with the year before, but no price recovery occurred in 2016 . The Saudi government initiated a new fiscal policy to mitigate the negative shock of the sharp decline in international oil prices. The public deficit in 2015 was the largest on record, at $15.8 \%$ of GDP (JADWA 2015).
Figure 6 shows the rate of GDP growth in 2009 and 2015 for the 13 Saudi provinces. The blue line in the figure is the bisectrix and indicates those provinces that had an identical rate of growth in both years. In 2009, the oil-rich Eastern Province had a severe recession: regional GDP decreased by $7.1 \%$. Meanwhile, Al-Riyadh stagnated, growing $0.3 \%$; Makkah Al-Mukarramah had a moderate recession, with its GDP decreasing by $2.1 \%$, probably due to the falling numbers of domestic pilgrims. Seven out of 13 provinces experienced negative growth that year. To sum up, the sharp declines in the international oil price in 2008-2009 and 2014-2015 had strong negative impacts on regional GDP, especially in the Eastern Province.

Figure 6. Share of population and GDP.

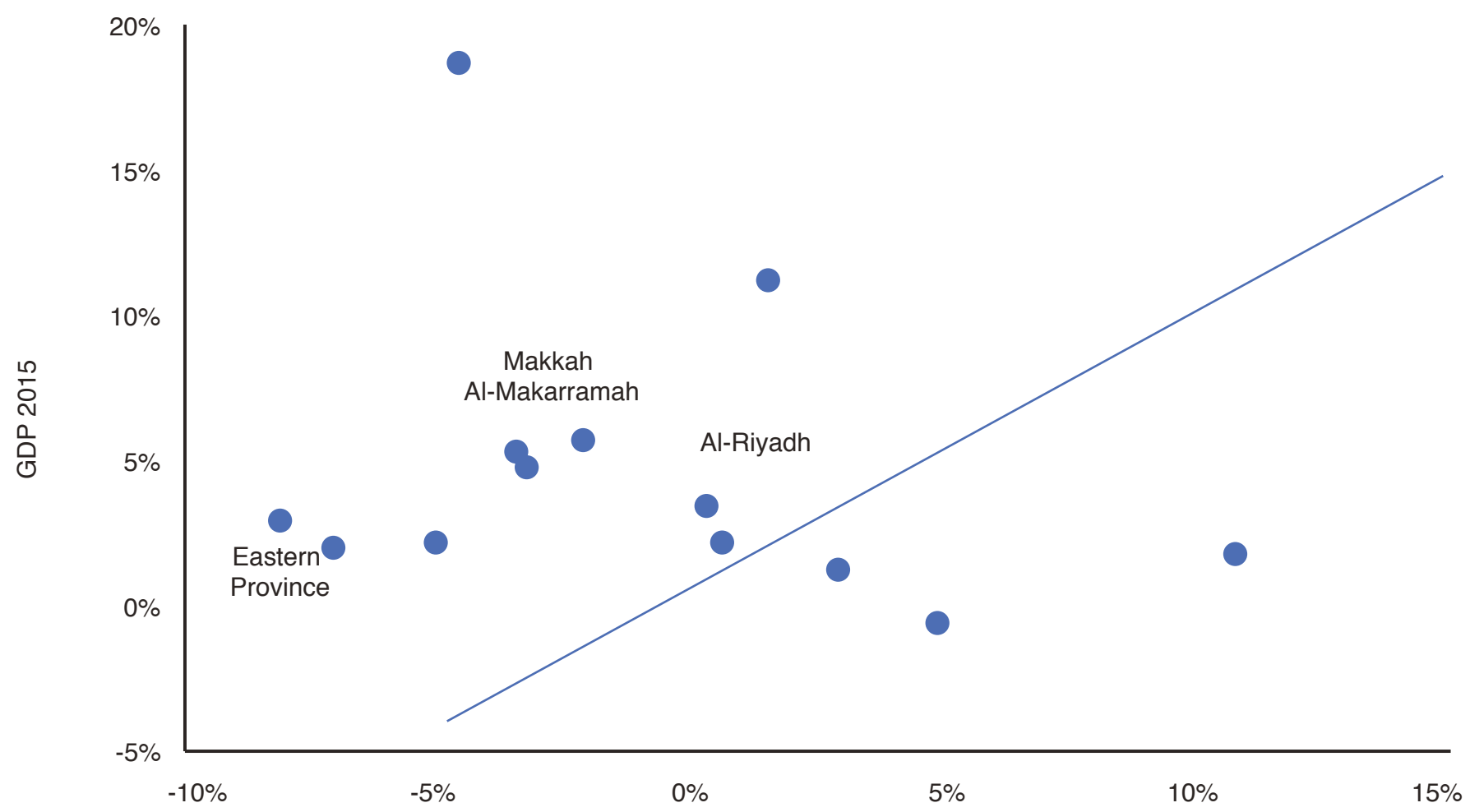

GDP 2009 
However, the impact of the oil price collapse of 2014-2015 differed from region to region because of the different economic circumstances of each province. Only one region, Al-Jouf, on the Jordanian border, had negative GDP growth in 2015. Al-Riyadh and the Eastern Province had moderate growth of between 2-3\%, Makkah Al-Mukarramah grew $5.7 \%$, and Al-Medinah Al-Monawarah grew $11.2 \%$. One reason for the latter's high growth rate is the inauguration in early 2015 of Prince Mohammad Bin
Abdulaziz International Airport in Medinah, with an initial capacity of 8 million passengers. The south region of Najran grew $18.7 \%$ in 2015 . This province has, since 2015, had an increasingly dynamic local economy. The main conclusion is that the social-economic policy deployed by the Saudi authorities, to mitigate the 2015 oil price decline, had a positive impact across all regions, including in the oil and gas rich Eastern Province. 


\section{Conclusions and Discussion}

This study set out to analyze the potential for using NOAA NTL images to estimate Saudi Arabia's regional GDP as a share of national GDP, the employment elasticities of regional GDP, the regional impacts of the 2008-2009 and 2014-2015 oil price declines, and the effects of economic policy on regional GDP growth.

It is possible to conclude from this analysis that the use of NOAA NTL images enables accurate estimations of regional GDP in Saudi Arabia's provinces. The rigorous econometric analysis conducted in this study made it possible to regionalize Saudi Arabia's economic activity and to identify and offer quantified information on the economic structure of the 13 provinces. This analysis opens the door to a more detailed economic analysis of Saudi Arabia's provinces.

This study shows that the Eastern Province, Al-Riyadh and Makkah Al-Mukarramah together account for almost $70 \%$ of Saudi Arabia's economically active population and generate around $60 \%$ of the country's total GDP. The Lorenz curve for Saudi Arabia illustrates a correlation between regional GDP and population. The regional estimation of GDP also offers quantified information on the different economic structures of each region and shows how GDP per capita varies among the provinces. For example, the GDP per capita of the oil rich Eastern Province is $70 \%$ higher than in tourism-dominated Makkah.

Although these results could be intuited from the quarterly employment statistics reported by GaStat, the ability to generate a granular analysis of regional economies using NTL will enable researchers to garner clearer insights into the economic structures of Saudi Arabian provinces.
Also, and perhaps more importantly, this methodology will allow for more in-depth analysis of how exposed Saudi Arabia's provinces are to international oil price shocks and the effects of economic policy in these regions. To illustrate this, we analyzed the differentiated effects of socio-economic policy during the two severe negative oil price shocks of 2008-2009 and 20142015. We concluded that the socio-economic policy deployed by the Saudi Arabian authorities to mitigate the 2015 oil price decrease had a positive impact across all regions, including the oil and gas rich Eastern Province.

Lastly, it is important to note that, because the NOAA VIIRS-DNB images are available in daily, monthly and yearly intervals, it is possible to increase the frequency with which GDP can be estimated for Saudi Arabia. This would allow for an estimation of regional GDP on a quarterly, or even monthly, basis. The methodology employed in this analysis could also be used to develop other regional socio-economic indicators for Saudi Arabia, based on NTL intensity. 


\section{References}

Chen, Xi, and William D. Nordhaus. 2011. "Using luminosity data as a proxy for economic statistics." Proceedings of the National Academy of Sciences 108 (21): 8589-8594. DOI: https://doi.org/10.1073/ pnas.1017031108

Cobb, Charles W., and Paul H. Douglas. 1928. "A Theory of Production." American Economic Review 18: 139-165.

Dickey, David A., and Wayne A. Fuller. 1981. "Likelihood ratio statistics for autoregressive time series with a unit root." Econometrica: Journal of the Econometric Society 49 (4): 1057-1072. DOI: https://doi.org/10.2307/1912517

Doll, Christopher N.H., Jan-Peter Muller and Jeremy G. Morley. 2006. "Mapping regional economic activity from night-time light satellite imagery." Ecological Economics 57 (1): 75-92. DOI: https://doi.org/10.1016/j. ecolecon.2005.03.007

Douglas, Paul H. 1976. "The Cobb-Douglas Production Function Once Again: Its History, Its Testing and Some New Empirical Values." Journal of Political Economy 84: 903-16. DOI: https://doi.org/10.1086/260489

Elvidge, Christopher D., Kimberly E. Baugh, Sharolyn J. Anderson, Paul C. Sutton, and Tilottama Ghosh. 2012. "The Night Light Development Index (NLDI): A spatially explicit measure of human development from satellite data." Social Geography 7 (1): 23-35. DOI: https://doi. org/10.5194/sg-7-23-2012

Elvidge, Christopher, Kimberly Baugh, Vinita Hobson, Eric Kihn, Herbert Kroehl, Ethan Davis, and David Cocero. 1997. "Satellite inventory of human settlements using nocturnal radiation emissions: A contribution for the global toolchest." Global Change Biology 3 (5): 387-395. DOI: https://doi.org/10.1046/j.1365-2486.1997.00115.x

Engle, Robert F., and Clive W. J. Granger. 1987. "Co-integration and Error Correction: Representation, Estimation and Testing." Econometrica 55(2): 251-276. DOI: https://doi.org/10.2307/1913236

General Authority of Statistics, Kingdom of Saudi Arabia (GaStat). 2019a. "Gross Domestic Product." https://www. stats.gov.sa/en/823
---. 2019b. "National Accounts." https://www.stats. gov.sa/en/52

Henderson, Vernon, Adam Storeygard, and David N. Weil. "Measuring economic growth from outer space." American Economic Review 102, no. 2 (2012): 994-1028. DOI: https://doi.org/10.1257/aer.102.2.994

Hainsworth, G.B. 1964. "The Lorenz Curve as a General Tool of Economic Analysis." Economic Record 40: 426-441. DOI: https://doi.org/10.1111/j.1475-4932.1964. tb02172. $x$

Hu, Yingyao, and Jiaxiong Yao. 2019. "Illuminating Economic Growth.” IMF Working Paper.

Jadwa Investment. 2015. "Saudi Arabia's 2015 fiscal budget." Accessed Jan. 25, 2019. www.jadwa.com/en/ download/2016-budget-2/gdp-report-15-6-2-1-2.

- - - 2015. "Saudi Arabia's 2009 fiscal budget." Accessed Jan. 25, 2019. http://www.jadwa.com/en/ download/2009-budget/saudi-arabias-2009-budget.

Johansen, Søren. 1988. "Statistical analysis of cointegration vectors." Journal of Economic Dynamics and Control 12 (2-3): 231-254. DOI: https://doi. org/10.1016/0165-1889(88)90041-3

Johansen, Søren, and Katarina Juselius. 1990. "Maximum likelihood estimation and inference on cointegration-with applications to the demand for money." Oxford Bulletin of Economics and Statistics 52 (2): 169-210. DOI: https://doi. org/10.1111/j.1468-0084.1990.mp52002003.x

- - - 1992. "Testing Structural Hypotheses in a Multivariate Cointegration Analysis of the PPP and the UIP for UK." Journal of Econometrics 53: 211-244. DOI: https://doi.org/10.1016/0304-4076(92)90086-7

Lopez-Ruiz, Hector, Nora Nezamuddin, and Abdelrahman Muhsen. 2019. "Estimating Freight Transport Activity Using Nighttime Lights Satellite Data in China, India and Saudi Arabia." KAPSARC methodology paper. DOI: https://doi.org/10.30573/ks--2019-mp07 
Mehraraa, Mohsen, and Kamran Niki Oskouib. 2007. "The sources of macroeconomic fluctuations in oil exporting countries: A comparative study." Economic Modelling 24: 365-379. DOI: https://doi.org/10.1016/j. econmod.2006.08.005

Mukin, Megha, and Keith Garret. 2018. "Tracking light from space: Innovative ways to measure economic development." Worldbank Blogs. http://blogs.worldbank. org/sustainablecities

NOAA. 2019. "DMSP \& VIIRS Nighttime Lights Time Series." Last accessed June 25, 2019. https://ngdc.noaa. gov/.

Perron, Pierre, and Timothy J. Vogelsang. 1992a. "Nonstationarity and level shifts with an application to purchasing power parity." Journal of Business \& Economic Statistics 10 (3): 301-320. DOI: https://doi.org/1 $0.1080 / 07350015.1992 .10509907$

- - - 1992b. "Testing for a unit root in a time series with a changing mean: corrections and extensions." Journal of Business \& Economic Statistics 10 (4): 467-470. DOI: https://doi.org/10.2307/1391823

Pesaran, M. Hashem, and Yongcheol Shin. 1998. "An autoregressive distributed-lag modelling approach to cointegration analysis." Econometric Society Monographs 31: 371-413. DOI: https://doi.org/10.1017/ ccol521633230.011

Pesaran, M. Hashem, Yongcheol Shin, and Richard J. Smith. 2001. "Bounds testing approaches to the analysis of level relationships." Journal of Applied Econometrics 16 (3): 289-326. DOI: https://doi.org/10.1002/jae.616
Pilling, David. 2018. "Why it is time to change the way we measure the wealth of nations." Financial Times, Jan. 9.

Phillips, Peter C.B., and Bruce E. Hansen. 1990. "Statistical inference in instrumental variables regression with I (1) processes." The Review of Economic Studies 57 (1): 99-125. DOI: https://doi.org/10.2307/2297545

Pinkovskiy, Maxim, and Xavier Sala-i-Martin.

"Lights, Camera... Income! Illuminating the National Accounts - Household Surveys Debate." The Quarterly Journal of Economics 131, no. 2 (2016): 579-631. DOI: https://doi.org/10.1093/qje/qjw003

Saudi Arabian Monetary Authority (SAMA). 2017. "Annual Statistics 2017."

Solow, Robert M. 1988. "Growth Theory and After." American Economic Review 78: 307-17.

U.S. Energy Information Administration. 2019. International Energy Statistics

Vogelsang, Timothy J., and Pierre Perron. 1998.

"Additional tests for a unit root allowing for a break in the trend function at an unknown time." International Economic Review 39 (4): 1073-1100. DOI: https://doi. org/10.2307/2527353 
Notes

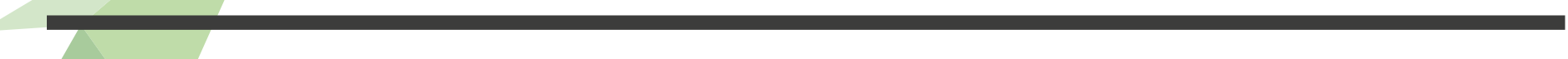




\section{Notes}


Notes

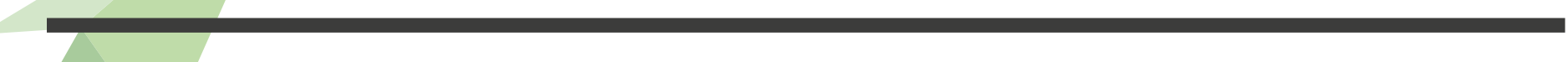




\section{Annex 1}

Figure A1. Regional employment, in persons.
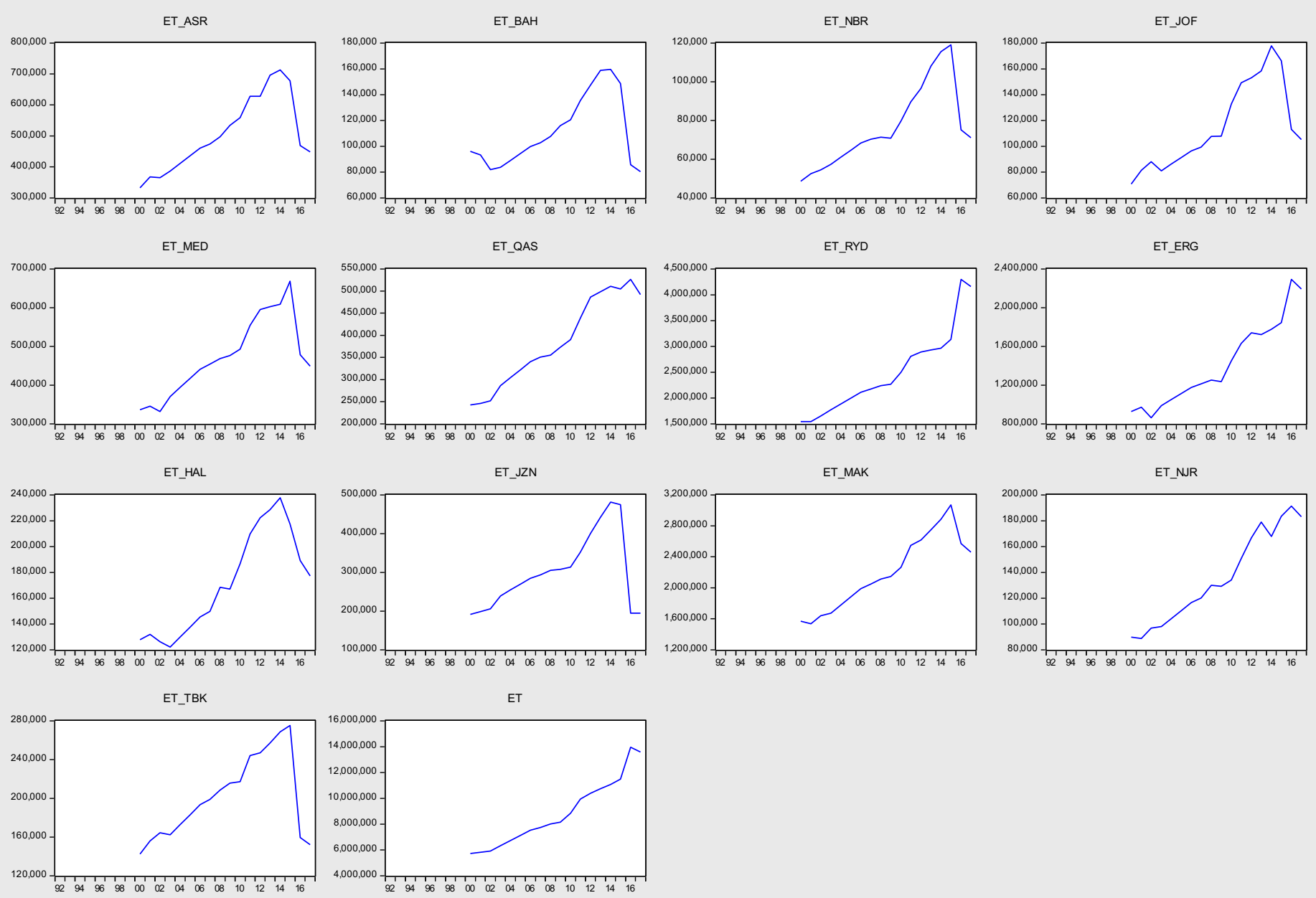

Note: ASR = Aseer; BAH = Al-Baha; NBR = Northern Borders; JOF = Al-Jouf; MED = Al-Medinah Al-Monawarah; QAS = Al-Qassim; RYD = Al-Riyadh; EPR = Eastern Province; HAL = Hail; JZN = Jazan; MAK = Makkah Al-Mukarramah; NJR = Najran; TBK = Tabouk 


\section{Acknowledgments}

We are grateful to Professor Andrea Bollino for his comments.

The views expressed in this paper are those of the authors and do not necessarily reflect the views of their affiliated institutions.

\section{About the Authors}

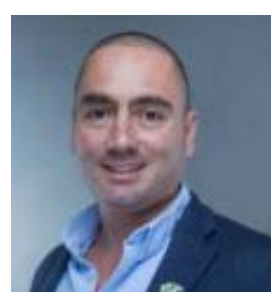

\section{Hector G. Lopez-Ruiz}

Hector is a research fellow specializing in transportation economics. He holds a Ph.D. in Economics from the University of Lyon.

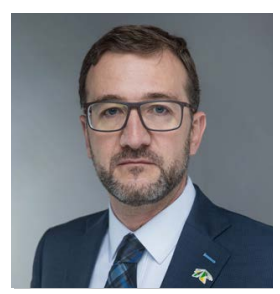

\section{Jorge Blazquez}

Jorge is a former research fellow specializing in energy and economics, with research interests in energy and macroeconomics, energy policies and transitions. He holds a Ph.D. in Economics from the Universidad Complutense de Madrid.

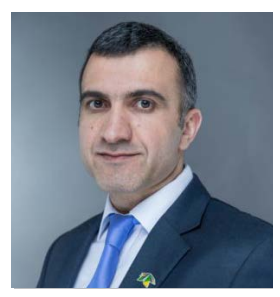

\section{Fakhri Hasanov}

Dr. Hasanov is a research fellow leading the KAPSARC Global Energy Macroeconometric Model (KGEMM) project. He is a member of the research program on forecasting at George Washington University. $\mathrm{He}$ is also an editorial board member of a number of international peer reviewed journals. His research interests and experience span econometric modeling and forecasting, building and applying macroeconometric models for policy purposes, and energy economics, with a particular focus on natural resource-rich countries.

\section{About the Project}

The KAPSARC Transport Analysis Framework (KTAF) studies and models global economic activity and freight transportation. For this, KTAF relies on open-source global data from satellites and the spatial distribution of different economic activities by broad sectors. The main objective of KTAF is to offer quantified insights on the effects of policy measures on transportation activities and energy consumption related to freight mobility. 
INAPSARC

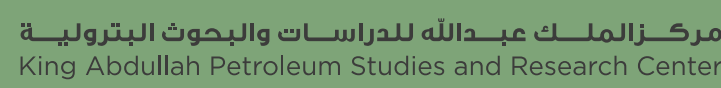

www.kapsarc.org 